\title{
Genes may solve hormone-disrupter debate
}

\section{Robert Triendl, Tokyo}

Disagreements over the health effects of socalled endocrine-disrupting chemicals could eventually be resolved by studying the genetic variablity of human and animal reactions to chemicals, researchers believe.

An international symposium on endocrine disrupters in Yokohama last month revealed a growing consensus that some of these chemicals can produce toxic effects at surprisingly low doses. But the meeting, the third in an annual series sponsored by the Japanese government's Environment Agency, found that the mechanisms underlying such effects are still poorly understood.

Endocrine disrupters are chemicals that affect human or animal health by interfering with normal hormonal processes. They are mediated by hormone receptors, and so could produce toxic effects at very low doses. Adherents to this hypothesis argue that applying standard risk assessments for toxic chemicals, which were developed mainly for carcinogens, does not adequately gauge the risk that endocrine disrupters pose to public health.

"The discussion at the first of these conferences was about whether 'low-dose effects' exist at all," says Hirozo Ueda, a director in the environmental health and safety division at the Japanese Environment Agency. "But now we are talking about which chemicals are associated with low-dose effects and which are not."

Researchers diverge sharply on the question of whether there is a threshold dose below which the chemicals can be regarded as safe. "There is no consensus yet that thresholds do not exist," says Robert

\section{Spanish leader lends ear to science}

\section{Xavier Bosch, Barcelona}

Spanish scientists, whose discontent with the workings of the country's science and technology system has been growing, last week won an unexpected opportunity to take their concerns directly to the prime minister, José María Aznar.

Aznar met six leading scientists on 9 January at the presidential palace, along with his science adviser Pablo Vázquez and the heads of the Ministry of Science and Technology and the research arm of the Ministry of Health.

The prime minister told the delegation that the planned 2000-04 public funds for

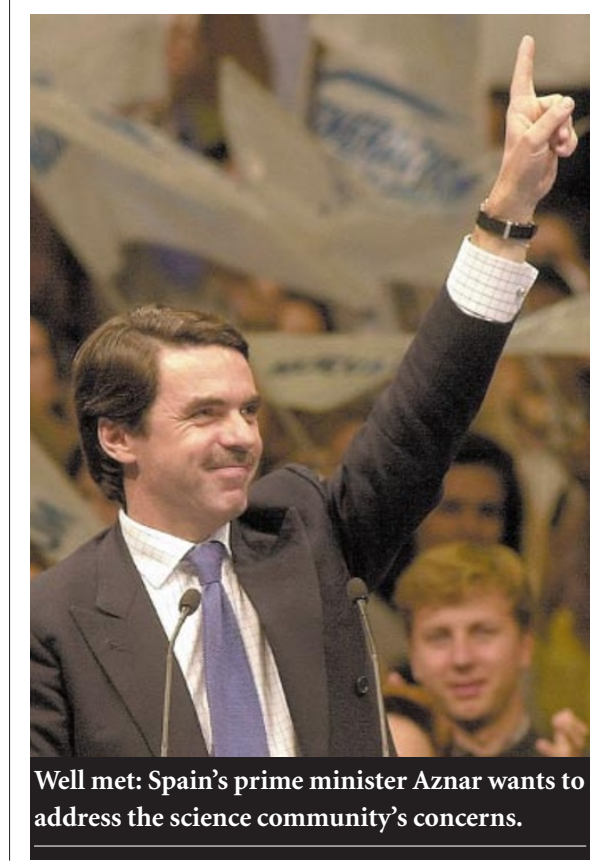

research were unlikely to be increased (Nature 402, 223; 1999). But, according to officials present, the meeting agreed on the acute need to prioritize areas of research more effectively, and to concentrate resources to build internationally competitive research teams such as that at the National Centre of Biotechnology in Madrid.

Other areas of agreement were the need to implement a continuous evaluation system for research, the need for new types of employment contract for researchers in the public sector, and the need for better links between the public and private sectors.

The scientists at the meeting included Mariano Barbacid, head of the National Centre for Cancer Research; Salvador Moncada, science adviser to the Institute of Cardiovascular Diseases and director of the Wolfson Institute for Biomedical Research at University College London; and Pere Puigdomènech, head of the Molecular Biology Institute in Barcelona. Juan Ramón Alaix, president of the Pharmacia drug company in Spain, represented the private sector.

The dialogue was very positive, says Barbacid, who is hoping it will increase the prime minister's support for Spain's scientific development.

Vázquez says that the meeting was Aznar's own initiative, and that the prime minister plans further meetings with other scientists every two or three months.

"Aznar wants to obtain information directly from the horse's mouth concerning the problems faced by the scientific community," Vázquez says.

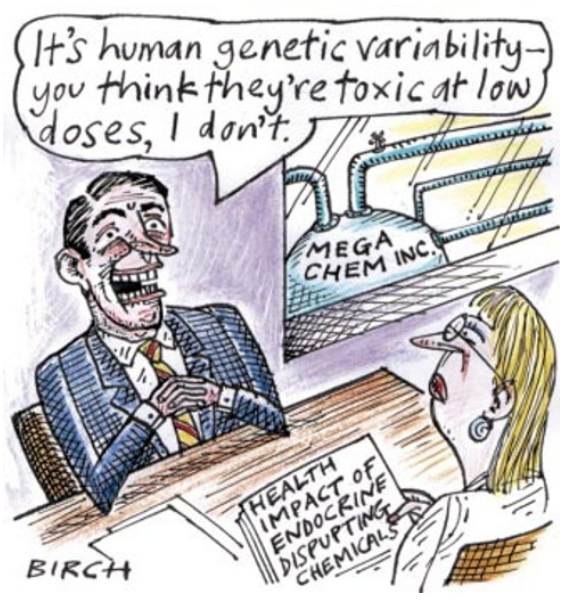

Kavlock, director of the reproductive toxicology division of the National Health and Environmental Effects Research Laboratory at the US Environmental Protection Agency.

Results from animal studies on suspect compounds, such as bisphenol A, a chemical widely used in the manufacture of plastics and glues, are inconclusive. "I am particularly perplexed by the data for bisphenol A, where some labs see it as a relatively potent oestrogen, and others fail to see much activity. This enigma needs to be understood at the mechanistic level," Kavlock says .

Pointing to data indicating that there is large genetic variability in the response to endocrine-disrupting chemicals, some scientists now argue that research in toxicogenetics, and novel tools such as geneexpression profiling and proteomics, may hold the key to understanding the effects of these chemicals in animals and humans.

"The evidence is that there can be as much as a 1,000 -fold, or greater, range of responses to these chemicals in different strains of mice. The regulatory default assumption of a ten-fold correction or safety factor for genetic variability is completely out of touch with the data," says Frederick vom Saal, a professor of biology at the University of Missouri-Columbia.

"Toxicogenetics clearly has the potential to make a difference to how toxicology is conducted," says Kavlock. But he points out that there are still problems with the approach. "It remains to be shown that these new technologies can indeed provide tools for understanding the modes of action of endocrine-disrupting chemicals, and whether they can be used to monitor exposure signals in populations," he says.

Government regulation of endocrine disrupters is still years away. The US Environmental Protection Agency is undertaking a programme to validate test methods for the chemicals that will take several years to complete. No regulation can be implemented until then. And officials in Japan say that regulation there is at least ten years off. 